ORIGINAL ARTICLE

\title{
Significant head cooling can be achieved while maintaining normothermia in the newborn piglet
}

\author{
J R Tooley, R C Eagle, S Satas, M Thoresen
}

Arch Dis Child Fetal Neonatal Ed 2005;90:F262-F266. doi: 10.1136/adc.2003.044305

See end of article for authors' affiliations .....................

Correspondence to: Professor Thoresen, Department of Child Health, St Michael's Hospital, Southwell Street, Bristol BS2 8EG, UK; marianne.thoresen@ bristol.ac.uk

Accepted 21 January 2005
Background: Hypothermia has been shown to be neuroprotective in animal models of hypoxia-ischaemia. It is currently being evaluated as a potentially therapeutic option in the management of neonatal hypoxicischaemic encephalopathy. However, significant hypothermia has adverse systemic effects. It has also recently been found that the stress of being cold can abolish the neuroprotective effects of hypothermia. It is hypothesised that selective head cooling (SHC) while maintaining normal core temperature would enable local hypothermic neuroprotection while limiting the stress and side effects of hypothermia.

Objective: To determine whether it is possible to induce moderate cerebral hypothermia in the deep brain of the piglet while maintaining the body at normothermia $\left(39^{\circ} \mathrm{C}\right)$.

Methods: Six piglets ( $<48$ hours old) were anaesthetised, and temperature probes inserted into the brain. Temperature was measured at different depths from the brain surface $\left(21 \mathrm{~mm}\left(T_{\text {deep }}\right.\right.$ brain $)$ to $7 \mathrm{~mm}$ $\left.\left(T_{\text {superficial brain }}\right)\right)$. After a 45 minute global hypoxic-ischaemic insult, each piglet was head cooled for seven hours using a cap circulated with cold water (median $8.9^{\circ} \mathrm{C}$ (interquartile range $7.5-14$ )) wrapped around the head. Radiant overhead heating was used to warm the body during cooling.

Results: During SHC it was possible to cool the brain while maintaining a normal core temperature. The mean (SD) $\mathrm{T}_{\text {deep brain }}$ during the seven hour cooling period was $31.1(4.9)^{\circ} \mathrm{C}$ while $\mathrm{T}_{\text {rectal }}$ remained stable at $38.8(0.4){ }^{\circ} \mathrm{C}$. The mean $\mathrm{T}_{\text {rectal }}-\mathrm{T}_{\text {deep brain }}$ difference throughout the cooling period was $9.8(6.1)^{\circ} \mathrm{C}$. The mean $T_{\text {skin }}$ required was $40.8(1.1)^{\circ} \mathrm{C}$. There was no evidence of skin damage secondary to these skin temperatures. During cooling only one piglet shivered.

Conclusions: It is possible to maintain systemic normothermia in piglets while significantly cooling the deeper structures of the brain. This method of cooling may further limit the side effects associated with systemic hypothermia and be feasible for premature infants.
$\mathrm{H}$ ypothermia after an hypoxic-ischaemic (HI) insult is neuroprotective in both human adults ${ }^{2}$ and neonatal animal models. ${ }^{3}$ Hypothermia is currently being applied in several large randomised studies to determine whether it is neuroprotective in human infants. A recent study of hypothermia after perinatal asphyxia in newborn infants showed a reduction in the number of children with cerebral palsy, except in those with the most severe brain injury. ${ }^{4}$ However, there are several worrying systemic effects of hypothermia, including potentially adverse effects on the cardiovascular, respiratory, immune, and haematological systems. ${ }^{5}$ Although safety data from pilot human studies have not shown any major deleterious effects after 72 hours of cooling, ${ }^{4}{ }^{7}$ the deeper the hypothermia, the more these side effects may become manifest. We have shown experimentally that the stress of being cold can nullify the neuroprotective effects of hypothermia. ${ }^{8}$ Therefore cooling only the head while maintaining normal core temperature has been proposed as a method of limiting further the stress and side effects of hypothermia.

Until now the main suggested application of hypothermia (within neonatal medicine) has been in the treatment of term infants with severe birth asphyxia, ${ }^{9}$ which accounts for one to two per 1000 live births in the United Kingdom. This condition is a major cause of both perinatal mortality and long term neurodisability. ${ }^{10}$ This approach has unfortunately missed the largest neonatal population suffering from long term neurodisability, which is the surviving preterm infant. ${ }^{11}$ Within this group, hypothermia has not been suggested as a neuroprotective treatment because of strong evidence that it is associated with both increased morbidity and mortality. ${ }^{12} 11$
Although the aetiology of preterm brain injury is not entirely clear, ${ }^{13}$ many of these infants will have damage secondary to $\mathrm{HI},{ }^{14}$ and hence hypothermia, if applied safely, could have a neuroprotective role.

Until recently, there have been only two ways of inducing cerebral hypothermia in infants (either total body cooling or head cooling combined with mild systemic hypothermia), both of which are associated with systemic hypothermia.

We have previously shown (using the Cool Care head cooling system; Olympic Medical, Seattle, Washington, USA) that it is possible to cool the brain to $5^{\circ} \mathrm{C}$ lower than core temperature $^{15}$ while allowing mild systemic hypothermia $\left(\mathrm{T}_{\text {rectal }} 35^{\circ} \mathrm{C}\right)$, and that, once established, the $\mathrm{T}_{\text {rectal }}-\mathrm{T}_{\text {deep brain }}$ gradient is stable for at least 24 hours. However, this degree of systemic hypothermia would not be acceptable in preterm infants.

The aim of this study was to determine whether it is possible to perform pure selective head cooling (SHC) and cool only the brain while maintaining total body normothermia, using both cooling and warming temperatures that could feasibly be applied in the preterm infant after HI.

\section{METHODS}

\section{Animal preparation}

All work was carried out under Home Office licence in accordance with United Kingdom guidelines. Six crossbred

Abbreviations: EEG, electroencephalography; $\mathrm{HI}$, hypoxic-ischaemic; $S H C$, selective head cooling; $T_{\text {rectal, }}$ rectal temperature; $T_{\text {scalp, }}$ scalp temperature; $T_{\text {deep brain, }}$ temperature at $\sim 21 \mathrm{~mm}$ brain depth; $T_{\text {mid-brain, }}$ temperature at $\sim 14 \mathrm{~mm}$ brain depth; $T_{\text {superficial brain, temperature at }}$

$\sim 7 \mathrm{~mm}$ brain depth; $T_{\text {skin, }}$, skin (thigh) temperature; $T_{\text {cap }}$, cap (circulating water) temperature 
Landrace/Large White piglets with postnatal age $<48$ hours and median weight of $1550 \mathrm{~g}$ (range 1170-1890) were obtained from an approved farm on the morning of the study. The piglets were maintained and monitored before, during, and after a severe, transient HI insult in accordance with the procedures reported previously. ${ }^{16}$

\section{Anaesthesia and ventilation}

Unrestrained animals were anaesthetised with 2.0\% halothane and nitrous oxide in a closed Perspex box, followed by transfer to an open incubator (Giraffe; DatexOhmeda, Hatfield, Hertfordshire, UK) for endotracheal intubation and mechanical ventilation (SLE 2000; SLE, South Croydon, Surrey, UK) with 0.7\% halothane, 65\% nitrous oxide, and $\sim 35 \%$ oxygen. Ventilation settings were adjusted to keep end tidal carbon dioxide between 4.5 and $5.5 \mathrm{kPa}$ during the study (except during the insult, when these settings were not changed). Before and after the HI insult, the inspired oxygen fraction was adjusted to maintain transcutaneous oxygen saturation between 95\% and 98\% (Masimo SET; Masimo Corporation, Irvine, California, USA). Nitrous oxide was discontinued 30 minutes before the insult, but halothane was continued until after the insult when head cooling was started. At this point, intravenous anaesthesia was initiated with a bolus dose of $4 \mathrm{mg} / \mathrm{kg}$ propofol and $30 \mu \mathrm{g} / \mathrm{kg}$ fentanyl followed by maintenance infusions of propofol $(4-12 \mathrm{mg} / \mathrm{kg} / \mathrm{h})$ and fentanyl $(10 \mu \mathrm{g} / \mathrm{kg} / \mathrm{h})$ for the seven hours of cooling until rewarming began. Pancuronium bromide ( $100 \mu \mathrm{g} / \mathrm{kg}$ ) was given as required during cooling to prevent prolonged shivering.

\section{Vascular access and fluids}

An ear vein was cannulated, and a 3.75\% dextrose $/ 0.45 \%$ saline infusion was started at $10 \mathrm{ml} / \mathrm{kg} / \mathrm{h}$ before the insult. After the insult, $5 \%$ dextrose $/ 0.45 \%$ saline was run at $5 \mathrm{ml} / \mathrm{kg} / \mathrm{h}$ to keep blood glucose within the desired range of 3-10 mmol/l (measured using Precision Plus glucose electrodes; Medisense UK Ltd, Abingdon, Oxfordshire, UK). Umbilical arterial and venous catheters were inserted to allow repeated blood gas sampling (Radiometer, Crawley, West Sussex, UK) and the infusion of fluids and drugs.

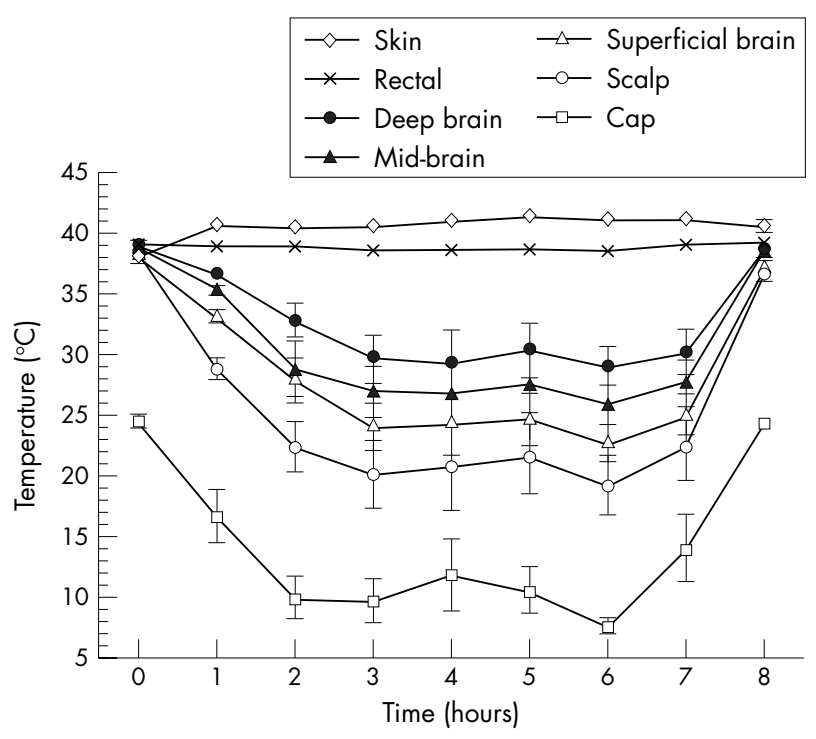

Figure 1 Temperature data from different sites in piglet brain during the seven hours of cooling, showing the temperature difference between rectal and deep brain. Values are mean (SE).

\section{Cardiac monitoring}

Continuous mean arterial blood pressure was measured from the umbilical artery catheter, and three lead electrocardiographic monitoring (IVY Biomedical, Branford, Connecticut, USA) was undertaken. During the insult, no lower limit for mean arterial blood pressure was set (unless it was associated with progressive bradycardia); otherwise a pressure $<40 \mathrm{~mm} \mathrm{Hg}$ during the study period was treated with up to two $10 \mathrm{ml} / \mathrm{kg}$ boluses of $0.9 \%$ saline followed, if it remained unsatisfactory, by inotropic support with dopamine (range $5-20 \mu \mathrm{g} / \mathrm{kg} / \mathrm{min}$ ).

\section{Temperature monitoring}

Temperatures were recorded from a rectal probe $\left(\mathrm{T}_{\text {rectal }}\right)$ inserted to $6 \mathrm{~cm}$ from the anal margin and from surface probes placed on the thigh $\left(\mathrm{T}_{\text {skin }}\right)$ and scalp $\left(\mathrm{T}_{\text {scalp }}\right)(400$ series; Yellow Springs Instrument Co, Yellow Springs, Ohio, USA). To measure intracerebral temperature at different depths, one temperature probe (containing three thermocouples $7 \mathrm{~mm}$ apart) was inserted into the brain at a depth of $2.2 \mathrm{~cm}$ from the brain surface (IT18-3 thermocouple; Physitemp Instruments Ltd, Clifton, New Jersey, USA). The deepest thermocouple recorded $\mathrm{T}_{\text {deep brain }}$ (depth $\sim 21 \mathrm{~mm}$ ), the most superficial probe recorded $\mathrm{T}_{\text {superficial }}(\sim 7 \mathrm{~mm}$ depth), and the probe in between recorded $\mathrm{T}_{\text {mid-brain }}$ ( $\sim 14 \mathrm{~mm}$ depth). The probe was embedded into a $1.0 \mathrm{~cm}$ diameter disc moulded from dental acrylic, which was sealed into an artificially made lateral fontanelle caudal to the bregma (as the newborn piglet has no patent fontanelle). Each probe was calibrated to within $\pm 0.1^{\circ} \mathrm{C}$, over a temperature range $20-40^{\circ} \mathrm{C}$, against a certified mercury-inglass thermometer (Zeal, London, UK). The rectal, skin, scalp, and intracerebral temperatures were recorded and stored at one minute intervals. The piglets were kept in an open incubator with sides $30 \mathrm{~cm}$ tall (Giraffe Incubator; Datex-Ohmeda). During the baseline period, the normal piglet core temperature of $39^{\circ} \mathrm{C}$ was maintained by an overhead radiant heater with a variable output from $0 \%$ to $100 \%$, positioned $80 \mathrm{~cm}$ above the piglet. During cooling, an insulating shield (Olympic Medical) incorporating reflective aluminium foil was placed over the piglet's head, to ensure that the overhead heater warmed only the exposed body below the neck.

\section{Electroencephalographic (EEG) monitoring}

Single channel parietal (interelectrode distance of $3 \mathrm{~cm}$ ) EEG was recorded during the insult and cooling-rewarming periods (Oxford Medilog 9000; Oxford Medical Systems Ltd, Abingdon, Oxfordshire, UK), as were amplitude integrated EEG recordings (Lectromed CFM monitor 60110; Olympic Medical).

\section{Head cooling cap}

A custom made cooling cap (Cool Care System; Olympic Medical) with a network of circulating water channels was used in this study. The volume of water held in the cap was $\sim 75 \mathrm{ml}$, and water circulated through the cap at $750 \mathrm{ml}$ per minute. The cap was fitted around the head and snout, avoiding contact with the neck. A disposable nappy was firmly secured over the cap to act as an outer insulating layer. The temperature of the circulating water was adjustable between 5 and $26^{\circ} \mathrm{C}$ as required throughout the cooling period.

After insertion of all the monitoring equipment, the piglet was placed in a prone position and rested for a 60 minute stabilising period. The piglets were then subjected to a 45 minute HI insult ${ }^{16}$ followed by cap cooling for seven hours, followed in turn by passive cerebral rewarming. Cooling was started by circulating cooled water through the cap, initially 
Table 1 Temperature $\left({ }^{\circ} \mathrm{C}\right)$ during the cooling-rewarming period

\begin{tabular}{lllll}
\hline & Baseline & 3 hours & 6 hours & After rewarming \\
\hline $\mathrm{T}_{\text {rectal }}$ & $39(0.3)$ & $38.8(0.5)$ & $38.8(0.4)$ & $39.2(0.2)$ \\
$\mathrm{T}_{\text {deep brain }}$ & $39.1(0.3)$ & $29.7(4.8)$ & $29(3.9)$ & $38.9(0.1)$ \\
$\mathrm{T}_{\text {mid-brain }}$ & $38.9(0.5)$ & $26.8(5.2)$ & $25.9(3.9)$ & $38.3(0.4)$ \\
$\mathrm{T}_{\text {superficial brain }}$ & $38.1(0.9)$ & $24.1(4.8)$ & $22.7(3.6)$ & $37.4(0.8)$ \\
$\mathrm{T}_{\text {scalp }}$ & $38.5(0.5)$ & $20.2(6.3)$ & $19.2(5.5)$ & $36.7(1.0)$ \\
$\mathrm{T}_{\text {skin }}$ & $38.1(1.5)$ & $40.6(1.2)$ & $41.2(0.4)$ & $40.6(1.3)$ \\
$\mathrm{T}_{\text {cap }}$ & Off & $9.7(4.4)$ & $7.6(1.4)$ & $24.5(0.9)$ \\
\hline &
\end{tabular}

set at $6{ }^{\circ} \mathrm{C}$, with the overhead heater turned on. Overhead heating power output was adjusted to maintain $\mathrm{T}_{\text {rectal }}$ at $39^{\circ} \mathrm{C}$ - that is, normothermia for pigs. The desired steady state was achieved by adjusting the cap temperature to that which allowed the maximal overhead heating to maintain a stable rectal temperature of $39^{\circ} \mathrm{C}$ (the cap water temperature that stabilised the rectal and deep brain temperatures over the seven hour period was $8.9^{\circ} \mathrm{C}(7.5-14)$, median (interquartile range)). After seven hours, cerebral rewarming was started by turning off the circulating water flow but leaving both the cooling cap and overhead reflective barrier in situ.

\section{Acute cerebral HI}

The inspired oxygen concentration was reduced abruptly to 4-6\% to reduce the real time EEG record to a background amplitude of $<7 \mu \mathrm{V}$. The insult was terminated after 45 minutes, and the piglet resuscitated with an increased inspired oxygen fraction until transcutaneous oxygen saturation was maintained at $95-98 \%$.

\section{Histopathology}

At the conclusion of the experiment, the brains were perfusion fixed, and, with the temperature probes in situ, left in $4 \%$ formaldehyde for seven days. The probes were then removed and the brain processed routinely for preparation of paraffin embedded blocks. The position of the temperature probe in each animal was confirmed from serially cut sections.

\section{Data analysis}

Data were stored and analysed using the software package Statview version 5.0.1 (Adept Scientific, Letchworth, Hertfordshire, UK). For comparisons of discrete variables within and between groups, Student's $t$ test (paired or unpaired) was used to compare parametric data, and Wilcoxon signed rank test for non-parametric data. Regression analysis was used to analyse associations between variables. $\mathrm{p}<0.05$ was considered significant (two tailed testing).

\section{RESULTS}

During SHC, it was possible to cool the brain while maintaining a normal systemic temperature (fig 1). The mean (SD) $\mathrm{T}_{\text {deep brain }}$ during the seven hour cooling period was $31.1(4.9)^{\circ} \mathrm{C}$ while $\mathrm{T}_{\text {rectal }}$ remained stable at $38.8(0.4)^{\circ} \mathrm{C}$. The mean $\mathrm{T}_{\text {rectal }}-\mathrm{T}_{\text {deep brain }}$ difference throughout the cooling period was $9.8(6.1)^{\circ} \mathrm{C}$. A temperature gradient developed across the brain from superficial to deep structures during cooling. Mean $\mathrm{T}_{\text {scalp }}$ measurements were the lowest at 22.7

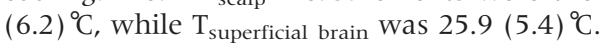

The ability to maintain this gradient did not decrease with time, and at the end of cooling it was still maintained at a mean of $9.4(4.1)^{\circ} \mathrm{C}$ (table 1 ). The ability to create this gradient was not influenced by either the size of the piglet or the severity of the HI insult (data not shown).
To maintain systemic normothermia and prevent hypothermia, it was necessary to use higher levels of radiant heat than previously reported. The mean $\mathrm{T}_{\text {skin }}$ required was $40.8(1.1)^{\circ} \mathrm{C}$ compared with $38.1^{\circ} \mathrm{C}$ at baseline. We observed no evidence of skin damage secondary to these higher skin temperatures.

The mean ( $\mathrm{SD}$ ) time for $\mathrm{T}_{\text {deep brain }}$ to return to normothermia after discontinuation of head cooling was short (36 (11) minutes), with a rate of temperature rise of $\sim 0.25^{\circ} \mathrm{C}$ per minute.

Table 2 shows cardiovascular and physiological variables during the cooling-rewarming periods. Heart rate was not significantly different from baseline levels during the period of cooling, but was significantly higher than baseline at the end of the HI insult $(p=0.03)$. Blood pressure was not significantly different at any time point of the experiment (although three of the animals required more than two boluses of volume, and two of these required an infusion of dopamine to maintain a normal blood pressure).

During the cooling period, only one piglet shivered and required pancuronium (this was despite a $\mathrm{T}_{\text {rectal }}$ of $39.2^{\circ} \mathrm{C}$ ).

Histopathological analysis confirmed the position of the temperature probes in the basal ganglia and showed no evidence of either bleeding or injury to the superficial brain tissue.

\section{DISCUSSION}

We have recently shown in newborn piglets that it is possible to cool $\mathrm{T}_{\text {deep brain }}$ to a lower temperature than $\mathrm{T}_{\text {rectal }}$ after an $\mathrm{HI}$ insult (using cap temperatures of $6-24^{\circ} \mathrm{C}$ ) while inducing mild systemic hypothermia. ${ }^{15}$ We have since confirmed that this method of achieving moderate cerebral hypothermia (brain temperature $30.1^{\circ} \mathrm{C}$ ) along with mild total body hypothermia is effective at inducing neuroprotection in our piglet model of HI injury. ${ }^{3}$

However, the use of total body hypothermia is not thought to be safe in the care of newborn preterm infants, as there is a clear link between hypothermia and increased mortality in this group. ${ }^{12}$

The depth and duration of hypothermia that is necessary to induce neuroprotection is uncertain. Most human infant studies that are in progress induce hypothermia for 72 hours, which is based solely on experimental studies on fetal sheep. ${ }^{17}$ However, human adult studies of therapeutic hypothermia have shown a beneficial effect of 12 hours of hypothermia, ${ }^{1}$ and experimentally in newborn pigs only three hours of hypothermia is neuroprotective if started immediately after an HI insult. ${ }^{18}$

Previous studies have reported attempts at SHC with normothermia. Laptook et $a l^{19}$ attempted to selectively cool the brain only in a piglet model of HI but required ice cold water $\left(1{ }^{\circ} \mathrm{C}\right)$ and a warming blanket set at $45^{\circ} \mathrm{C}$ to maintain rectal temperature at normothermia. Despite these extreme temperatures, which would not be acceptable in neonatal practice, they could not lower brain temperature below $35^{\circ} \mathrm{C}$. Moreover, when hypoxia was applied during SHC, the deep 
Table 2 Physiological variables during the cooling-rewarming period

\begin{tabular}{|c|c|c|c|}
\hline & $\begin{array}{l}\text { Heart rate } \\
\text { (beats/min) }\end{array}$ & $\begin{array}{l}\text { MABP } \\
(\mathrm{mm} \mathrm{Hg})\end{array}$ & $\begin{array}{l}\text { Arterial } \\
\text { blood pH }\end{array}$ \\
\hline Baseline & $146(134-167)$ & $50(44-56)$ & $7.51(7.41-7.58)$ \\
\hline End of hypoxia & $208(178-240)^{*}$ & $37(27-54)$ & $7.10(7.05-7.20)$ \\
\hline Cooling 3 hours & $182(142-240)$ & $46(42-53)$ & $7.39(7.36-7.47)$ \\
\hline Cooling 6 hours & $157(130-209)$ & $53(45-61)$ & 7.45 (7.36-7.55) \\
\hline End of rewarming & $156(126-200)$ & $48(42-55)$ & $7.49(7.45-7.54)$ \\
\hline
\end{tabular}

brain temperature rose markedly and the $T_{\text {rectal }}-T_{\text {deep }}$ brain gradient fell to about $1^{\circ} \mathrm{C}$. Iwata et $a^{20}$ also found that, in normothermic pigs, they were only able to induce mild selective cerebral hypothermia before an HI insult if the coolant temperature around the head was $0^{\circ} \mathrm{C}$. Further attempts at inducing cerebral hypothermia using coolant temperatures of $10^{\circ} \mathrm{C}$ were not successful unless rectal temperature was allowed to fall by $1{ }^{\circ} \mathrm{C}$, and, even in this instance, deep brain temperature did not fall below $35^{\circ} \mathrm{C}$. Neither of these experiments was performed after HI, and we have shown previously that the gradient between rectal and brain temperature is reduced after an HI Insult. ${ }^{21}$ In this study, however, using the Cool Care System and radiant overhead heating, we have been able to induce moderate cerebral hypothermia, producing cerebral temperatures that have been previously shown to be neuroprotective in our model. $^{3}$

Several observations from these data require further comment. Firstly, no fall in heart rate was seen during this method of cooling. This is in contrast with our previous experience with head cooling associated with systemic hypothermia, when we found a fall in heart rate to $60 \%$ of normothermic values. ${ }^{3}$ This may have potential importance as it is thought that one of the mechanisms of hypothermic neuroprotection is reduced metabolic demand. Secondly, we have previously reported that stress may reduce the effectiveness of hypothermia as a neuroprotective treatment, and hypothermia has been shown to induce intense shivering and raised stress levels in the newborn pig. ${ }^{8}$ During combined SHC and mild systemic hypothermia, all piglets shivered and required paralysis to stop it. ${ }^{3}$ It was interesting that only one piglet in this study shivered and needed paralysis. Hence in five out of six piglets, there were no physiological attempts at thermogenesis despite the profoundly cold cerebral tissue, confirming that body skin temperature is the main sensory input for thermoregulation. Thirdly, this method of cooling does not appear to confer any beneficial effect on the cardiovascular system recovering from HI injury, as the proportion of pigs $(50 \%)$ requiring inotropic support in this study was similar to that previously reported.

A concern regarding the safety of this method of SHC is the need to increase radiant heat to achieve skin temperatures as much as $2^{\circ} \mathrm{C}$ higher than core temperature. This increased heat input could lead to high evaporative water loss in a preterm human infant. However, this requirement for increased heat input may be species specific, as the pig has a thick epidermis with coarse hair and hence requires more heat to permeate through this barrier. In this model, there was no evidence of skin injury. Also in this particular set of experiments, our aim was to try to cool the brain as much as technically possible. In a true study of the protective effects of cerebral hypothermia, we would only aim to do this by $3-4^{\circ} \mathrm{C}$ (rather than the $9.8^{\circ} \mathrm{C}$ achieved in this study). Consequently less cooling and therefore less heating would be required. Another concern is the need to induce profound superficial cerebral hypothermia to achieve moderate hypothermia in the deep structures of the brain. Parkins et al, ${ }_{1}^{22}$ using a cold perfusion model of selective cooling in the canine brain, found that only temperatures below $12^{\circ} \mathrm{C}$ led to brain pathology from hypothermia per se. In our current study, histological examination found no evidence of cortical brain injury. This is in contrast with our previously reported results in which significant cortical damage was found after an HI insult at only six hours normothermic survival. ${ }^{23}$ In the present method of cerebral hypothermia, there appears to be a wide variation in the extent of deep cerebral hypothermia $\left(\mathrm{SD} 4.9^{\circ} \mathrm{C}\right.$ ). We previously speculated in our model paper of SHC combined with mild systemic hypothermia ${ }^{21}$ that this variation was due to multiple factors, including the severity of the HI insult and variations in cerebral blood flow (unpublished data).

The final concern about the safety of this method of SHC is the potentially deleterious effects of rapid changes in cerebral temperature during rewarming. Despite attempts to slow the rate of rewarming by keeping the cap full of cold water in situ (as a heat sink), cerebral temperature had returned to normothermia in all pigs in less than one hour, and these large abrupt changes in cerebral temperature of $0.25^{\circ} \mathrm{C} / \mathrm{min}$ were accomplished solely by turning off the cooling machine. In the absence of measurements of deep brain temperature, these fluctuations would have gone unnoticed.

It is by no means certain that it is possible to selectively cool the newborn human brain (especially as there is as yet no way of measuring brain temperature safely). Corbett and Laptook $^{24}$ were unable to show in the normal human adult a reduction in brain temperature of more than $0.4^{\circ} \mathrm{C}$ using localised head cooling leading to scalp temperatures of $16^{\circ} \mathrm{C}$. Mellergard ${ }^{25}$ attempted to selectively head cool human adults and was unable to cool the deep brain at all using an "ice cap" surrounding the head. In fact, his studies showed that epidural temperature only fell by $1{ }^{\circ} \mathrm{C}$ (whereas in our study we were able to reduce superficial brain temperature $(7 \mathrm{~mm}$ deep) to $16^{\circ} \mathrm{C}$ below core temperature). A paper describing numerical modelling of heat exchange in the newborn human head postulated that it would not be possible to cool any tissue in the brain deeper than $2 \mathrm{~cm}$ from the scalp. ${ }^{26}$ This model did not take into account heat loss from arteriovenous heat exchange, which is known to be important. ${ }^{27}$ The fact that we were able to create a mean temperature gradient between $\mathrm{T}_{\text {rectal }}$ and $\mathrm{T}_{\text {deep brain }}$ of $9.8^{\circ} \mathrm{C}$ at this depth is very encouraging. One can speculate that it should be easier to cool a small, more immature brain with lower cerebral blood flow, as in the premature baby, than that of a large term infant.

The use of hypothermia as a treatment in premature brain injury requires further study in experimental models before its use in human infants. The aetiology of preterm perinatal brain injury is less clear than in the term infant, but HI plays an important role, not only in those injuries sustained around the time of birth, ${ }^{13}$ but also those sustained in the postnatal period. Until now, hypothermia has not been studied with any vigour in preterm models of brain injury because it was 
felt that the systemic effects would counteract any potential benefit. The piglets used in this study were healthy, born at term, and with brain maturation similar to that of a term human infant, and so cannot be used in this instance as a model of the preterm brain for the assessment of the neuroprotective effects of hypothermia. However, from a practical point of view, the head size and weight of the piglets in this study were of human preterm infant proportions. The head circumference of a newborn piglet is $26 \mathrm{~cm}$, which is equivalent to a preterm infant at 27 weeks gestation. Our findings that it is possible to cool the brain without cooling the body will hopefully stimulate research into the benefit of hypothermia in the field of preterm brain injury.

\section{CONCLUSION}

We have shown in this study that it is possible to maintain systemic normothermia while significantly cooling the deeper structures of the brain after an HI insult. This method of cooling may further limit the side effects associated with systemic hypothermia and may be feasible for use in premature infants in experimental studies.

\section{ACKNOWLEDGEMENTS}

We are grateful for financial support from SPARKS (UK), The Laerdal Foundation for Acute Medicine, and the Wellcome Trust. We are also grateful to Olympic Medical for lending us the Cool Care System, Masimo Corporation for the pulse oximeter, Datex-Ohmeda for the Giraffe incubator, and Radiometer for the use of a blood gas analyser.

\section{Authors' affiliations}

J R Tooley, S Satas, M Thoresen, Department of Child Health, St Michael's Hospital, University of Bristol, UK

R C Eagle, Department of Anatomy, School of Veterinary Science, University of Bristol, UK

Competing interests: none declared

\section{REFERENCES}

1 Bernard SA, Gray TW, Buist MD, et al. Treatment of comatose survivors of outof-hospital cardiac arrest with induced hypothermia. N Engl J Med 2002;346:557-63.

2 Hypothermia. After.Cardiac.Arrest.Study.Group. Mild therapeutic hypothermia to improve the neurologic outcome after cardiac arrest. NEngl J Med 2002:346:549-56.

3 Tooley JR, Satas S, Porter H, et al. Head cooling with mild systemic hypothermia in anesthetized piglets is neuroprotective. Ann Neurol 2003;53:65-72.

4 Gluckman PD WJ, Azzopardi D, Ballard R, et al. Selective head cooling with mild systemic hypothermia to improve neurodevelopmental outcome following neonatal encephalpathy. Lancet 2005;365:663-70.
5 Schubert A. Side effects of mild hypothermia. I Neurosurg Anesthesiol 1995;7:139-47.

6 Thoresen M, Whitelaw A. Cardiovascular changes during mild therapeutic hypothermia and rewarming in infants with hypoxic-ischemic encephalopathy. Pediatrics 2000; 106:92-9.

7 Gunn AJ, Gluckman PD, Gunn TR. Selective head cooling in newborn infants after perinatal asphyxia: a safety study. Pediatrics 1998;102:885-92.

8 Thoresen M, Satas S, Loberg EM, et al. Twenty-four hours of mild hypothermia in unsedated newborn pigs starting after a severe global hypoxic-ischemic insult is not neuroprotective. Pediatr Res 2001;50:405-11.

9 Thoresen M. Cooling the newborn after asphyxia: physiological and experimental background and its clinical use. Semin Neonatol 2000;5:61-73.

10 Volpe J. Neurology of the newborn. Philadelphia, PA: WB Saunders, 2000:331-94.

11 Costeloe K, Hennessy E, Gibson AT, et al. The EPICure study: outcomes to discharge from hospital for infants born at the threshold of viability. Pediatrics 2000;106:659-71.

12 Silverman $\mathbf{W}$. The influence of the thermal environment upon the survival of newly born premature infants. Pediatrics 1958:876-86.

13 Hagberg H, Peebles D, Mallard C. Models of white matter injury: comparison of infectious, hypoxic-ischemic, and excitotoxic insults. Ment Retard Dev Disabil Res Rev 2002;8:30-8.

14 Volpe J. Brain injury in the premature infant: overview of clinical aspects, neuropathology, and pathogenesis. Semin Pediatr Neurol 1998; 5: 135-51.

15 Tooley J, Satas S, Eagle R, et al. Significant selective head cooling can be maintained long-term after global hypoxia ischemia in newborn piglets. Pediatrics 2002; 109:643-9.

16 Thoresen M, Haaland K, Loberg EM, et al. A piglet survival model of posthypoxic encephalopathy. Pediatr Res 1996;40:738-48

17 Gunn AJ, Gunn TR, de Haan HH, et al. Dramatic neuronal rescue with prolonged selective head cooling after ischemia in fetal lambs. J Clin Invest 1997;99:248-56.

18 Haaland K, Loberg EM, Steen PA, et al. Posthypoxic hypothermia in newborn piglets. Pediatr Res 1997:41:505-12.

19 Laptook AR, Shalak L, Corbett RJ. Differences in brain temperature and cerebral blood flow during selective head versus whole-body cooling Pediatrics 2001;108:1103-10.

20 Iwata $\mathrm{O}$, Iwata $\mathrm{S}$, Tamura $\mathrm{M}$, et al. Brain temperature in newborn piglets under selective head cooling with minimal systemic hypothermia. Pediatr Int 2003;45: 163-8.

21 Thoresen $M$, Simmonds $M$, Satas S, et al. Effective selective head cooling during posthypoxic hypothermia in newborn piglets. Pediatr Res 2001;49:594-9.

22 Parkins WM, Jensen JM, Vars HM. Brain cooling in the prevention of brain damage during periods of circulatory occlusion in dogs. Ann Surg 1954; 140:284-9.

23 Thoresen M, Hallstrom A, Whitelaw A, et al. Lactate and pyruvate changes in the cerebral gray and white matter during posthypoxic seizures in newborn pigs. Pediatr Res 1998;44:746-54.

24 Corbett RJT, Laptook AR. Failure of localized head cooling to reduce brain temperature in adult humans. Neuroreport 1998;9:2721-5.

25 Mellergard P. Changes in human intracerebral temperature in response to different methods of brain cooling. Neurosurgery 1992;31:671-7.

26 Van Leeuwen GM, Hand JW, Lagendijk JJ, et al. Numerical modeling of temperature distributions within the neonatal head. Pediatr Res 2000;48:351-6.

27 Cabanac M, Caputa M. Natural selective cooling of the human brain: evidence of its occurrence and magnitude. J Physiol 1979;286:255-64. 